\title{
Os Consórcios Intermunicipais de Saúde e o Sistema Único de Saúde
}

\author{
Intermunicipal Health Consortiums \\ and the Brazilian Public Health System
}

\footnotetext{
${ }^{1}$ Departamento de Ciências Sociais, Escola Nacional de Saúde Pública, Fundação Oswaldo Cruz. Rua Leopoldo Bulhões 1480, 9 o andar, Rio de Janeiro, $R J$ 21041-210, Brasil.
}

\begin{abstract}
Municipalities (or counties) in the interior of Brazil have encountered difficulties in implementing the public health system as regulated by the 1988 National Constitution. The lack of human and financial resources, accessible technology, and adequate physical infrastructure, plus the remote location of public health facilities, constitute the most common obstacles that have led municipal managers to seek administrative alternatives. Intermunicipal Health Consortiums have been formed within that framework and present an innovative approach to the administration of the Brazilian public health system. This study describes the current status of the Health Consortiums and their distribution and organization in different regions of the country. This administrative strategy has been used mainly in small municipalities, especially in States from the Southeast and South. The strategy involves different interests and forms of implementation.
\end{abstract}

Key words Local Health Systems; Health Policy; Public Sector

Resumo Os municípios do interior do Brasil têm enfrentado dificuldades na implementação do Sistema Único de Saúde, regulamentado na Constituição de 1988. A falta de recursos humanos $e$ financeiros, a dificuldade de acesso a uso de tecnologias e a inexistência de estruturas físicas adequadas, além da distância que dificulta o atendimento à saúde, são os entraves mais comuns, que levam os dirigentes municipais a procurar alternativas de gestão. Os Consórcios Intermunicipais de Saúde surgem nesta perspectiva, apresentando-se como uma prática de gestão inovadora no sistema de saúde no Brasil. Este estudo descreve a situação atual dos consórcios de saúde, sua distribuição e organização nas diferentes regiões do país. Esta modalidade de gestão é utilizada principalmente em municípios pequenos e tem uma grande concentração nos estados do Sudeste e Sul do Brasil. Seu desenvolvimento é mediado por diferentes interesses e formas de implantação.

Palavras-chave Sistemas Locais de Saúde; Política de Saúde; Setor Público 


\section{Introdução}

O sistema público de saúde no Brasil vem enfrentando nas últimas décadas consideráveis modificações. Desde um sistema centralizador e privativista que na década de 70 excluía as parcelas mais carentes da população da assistência à saúde, até as modificações substanciais ocorridas após o Movimento de Reforma Sanitária que culminaram com a consolidação do Sistema Único de Saúde (SUS) na Constituição de 1988 (Brasil, 1988).

No decorrer da década de 90, assistimos a inúmeras discussões sobre formas de implementar uma política pública de saúde que fosse integral e universal, enfrentando a falta de recursos financeiros, o surgimento de novas tecnologias e equipamentos, a falta de recursos humanos preparados para atuar no sistema público de saúde e, entre outros tantos problemas, o crescimento acelerado das empresas privadas de saúde.

Na tentativa de implementar o sistema público de saúde em municípios do interior do Brasil, onde os problemas são inúmeras vezes maiores, é que surgem novas práticas de gestão.

Ao se buscar práticas de gestão inovadoras que venham concretizar os princípios do SUS no sentido de melhorar o atendimento à população daquele determinado território, o primeiro princípio de que se lança mão é o da integralidade. Entende-se que a prática do sistema de saúde preconizada na Constituição deve buscar a melhoria da saúde da população como um todo, em todos os níveis de atenção. Nesta perspectiva, os Consórcios Intermunicipais de Saúde, seriam uma forma de disponibilizar desde os níveis mais elementares até os mais complexos de atendimento necessários ao bem estar.

Este trabalho, que ora apresentamos, é fruto de dois anos de estudo sobre o tema dos Consórcios Intermunicipais de Saúde, um assunto atualmente debatido amplamente no país. A análise buscou compreender de que forma os consórcios estão se organizando; quais os interesses em jogo; como estão distribuídos por regiões e de que forma estão viabilizando práticas de saúde mais includentes e/ou excludentes no âmbito do SUS.

O estudo foi realizado a partir de um levantamento junto às Secretarias Estaduais de Saúde dos 26 estados e do Distrito Federal no período de maio a outubro de 1997, utilizando um questionário contendo perguntas sobre a estrutura e funcionamento dos consórcios. Os dados populacionais utilizados foram fornecidos pela Fundação Instituto Brasileiro de Geografia e Estatística (IBGE, 1996).

\section{O surgimento dos consórcios intermunicipais}

Os consórcios intermunicipais são uma prática antiga de gestão, citada na Constituição paulista de 1891, na legislação federal em 1937, novamente em 1967 e suprimida por emenda constitucional em 1969 (Costa Filho, 1955; Almeida, 1958; Tavares, 1977). São melhor detalhados pelo Direito Administrativo e definidos por Torres (1995:35): "Consórcio, do latim consortiu, implica a idéia de associação, ligação, união e, no âmbito das relações intermunicipais, nada mais apropriado do que a formação de entidades visando o estudo, o acompanhamento, o diagnóstico das soluções que, via de regra, envolvem municípios limítrofes e com problemas que se identificam numa ordem cada vez mais crescente em função de forte demanda dos administrados".

A formação de consórcios não obedece a uma única lógica, mas aos interesses e disponibilidades de uma dada região, conformando diversos modos de atuação e permitindo o seu aprimoramento, inclusão ou não de municípios, agrupamento de municípios que, pela lógica da proximidade, pode não pertencer ao estado/sede do consórcio. Da mesma forma, podem assumir objetivos diversos, ou seja, formarem consórcios para prover ou melhorar condições de estradas, saneamento de regiões, instalações de energia elétrica, melhoria da rede de serviços de saúde, a viabilização de hospitais ou implementar a assistência de saúde de determinadas regiões.

\section{Os consórcios intermunicipais no sistema de saúde brasileiro}

Debates sobre a prática de consorciamento têm sido travados dentro da agenda pública do setor de saúde no país. No entanto, muito pouco se tem conseguido avançar, pois as experiências concretas ainda são muito recentes. A instituição dos consórcios de saúde foi citada na Lei Orgânica da Saúde, a de no 8.080/90 (Brasil, 1990a) e na Lei no 8.142/90 (Brasil, 1990b), como uma alternativa para os municípios desenvolverem as ações de saúde dentro do processo de municipalização.

Vianna (1996) aponta que o processo de descentralização do setor de saúde foi influenciado pela reforma fiscal de 1988. Isto teria ocasionado uma desigualdade na implementação do SUS nas diferentes regiões do país, sendo que a retração dos investimentos federais na área de saúde não foi compensada de maneira 
homogênea pela elevação dos investimentos municipais. Desta forma, a mesma autora refere-se que foi efetivamente implantado um modelo de "descentralização caótico" em substituição à descentralização planejada anteriormente prevista para a implementação do SUS (Vianna, 1996).

As necessidades e carências apresentadas pelos municípios de pequeno porte para a implementação de ações de saúde - otimização de estrutura física, falta de recursos materiais, apoio diagnóstico deficiente, acesso a novas tecnologias médicas, somadas à escassez de recursos humanos especializados, principalmente pela baixa remuneração - aliadas às deficiências peculiares ao interior do país, têm elevado a busca de parcerias para o processo de gestão e organização dos sistemas de saúde.

A política do governo durante a década de 90 institui diversos programas e normas para operacionalizar o sistema, entre elas destacamse a Norma Operacional Básica - NOB 01/91 (MS, 1991), a NOB 01/93 (MS, 1993), Projeto REFORSUS (Recuperação da estrutura física, tecnológica e desenvolvimento institucional) (MS, 1996), a NOB 01/96 (MS, 1997a) e com ela o Piso Assistencial Básico - PAB (que visa uma maior igualdade na distribuição financeira entre os municípios, estimulando o Programa de Agentes Comunitários de Saúde - PACS - e Programas de Saúde da Família - PSF). O ministério lança também o documento "1997 - O Ano da Saúde no Brasil” (MS, 1997b), onde cita a necessidade de criação dos consórcios. No mesmo ano, convoca a primeira oficina sobre consórcios, editando o manual "Os Consórcios e a Gestão Municipal em Saúde” (MS, 1997c).

Com a publicação da Norma Operacional Básica do Ministério da Saúde em 1996 (MS, 1997a), os Consórcios Intermunicipais de Saúde passaram a ser considerados, no contexto da regionalização e hierarquização da rede de serviços, como sendo estratégias para articulação e mobilização dos municípios, com coordenação estadual, de acordo com características geográficas, demanda, perfil epidemiológico, oferta de serviços e, principalmente, a vontade política expressa pelos diversos municípios de constituírem um consórcio ou estabelecer qualquer outra relação de caráter cooperativo (NOB - SUS no 01/1996).

A publicação desta norma tem despertado interesse por parte dos gestores municipais em adotar o sistema de consórcios. O crescimento desta prática de gestão pode ter conotações distintas em uma análise mais aprofundada sobre a sua forma de implantação. Se por um lado a conformação dos consórcios é feita por meio de amplos debates dos atores envolvidos e de acordo com a real necessidade de assistência da população dos municípios, por outro lado, pode estar acompanhada de interesses clientelistas de gestores ou comprometida com o aumento da "resolutibilidade" do serviço de saúde de um determinado município, viabilizando a prática de terceirização ou do sistema de cooperativas de trabalhadores.

Diferentes tendências sobre a formação de consórcios de saúde foram apontadas anteriormente (Gontijo et al., 1994; Mendes, 1996). Carvalho \& Santos (1995:110) citam o consórcio como "um importante instrumento de organização e gestão do SUS" e chamam a atenção para o fato de que, embora a entidade Consórcio Intermunicipal tenha pessoa jurídica civil de direito privado (na maioria dos casos), ela trabalha com recursos públicos vindos dos municípios, estados e da união e pode receber outros recursos provenientes de fontes diversas. Portanto, os princípios básicos para a administração de um consórcio devem ser os que regem a administração pública, como no que diz respeito a concurso público para a contratação de pessoal, licitações para a aquisição de bens e insumos e também, quanto à prestação de contas dos recursos a ser efetuada de forma transparente.

\section{A situação dos consórcios intermunicipais de saúde no Brasil}

No Brasil, atualmente, existem sete Unidades Federativas que possuem Consórcios Intermunicipais de Saúde. Estes consórcios, totalizando 91, estão distribuídos de maneiras diversas, em contextos sócio-econômicos diferenciados (como é peculiar em nosso país) e também organizados distintamente.

Tomando a população do Brasil em agosto de 1996, segundo dados do IBGE (1996), de 157.079.573 habitantes e a população dos sete estados que possuem Consórcios Intermunicipais de Saúde (79.852.161 habitantes), verifica-se (Tabela 1), que os consórcios abrangem proporcionalmente $23,3 \%$ da população destes estados.

O Brasil possui 5.509 municípios (IBGE, 1996), sendo que nos estados estudados somam 3.006. Os 91 consórcios existentes abrangem 1.204 municípios, ou seja, 40\% dos municípios nos estados trabalhados e $22 \%$ do total das cidades brasileiras. 
Distribuição dos municípios consorciados segundo estados e população coberta. Brasil, 1997.

\begin{tabular}{|c|c|c|c|c|c|}
\hline $\begin{array}{l}\text { Estados com } \\
\text { consórcios }\end{array}$ & População total & $\begin{array}{l}\text { Número de } \\
\text { municípios }\end{array}$ & $\begin{array}{l}\text { Número de } \\
\text { consórcios }\end{array}$ & $\begin{array}{l}\text { Número de } \\
\text { municípios/ } \\
\text { consórcio }\end{array}$ & $\begin{array}{l}\text { População } \\
\text { coberta }\end{array}$ \\
\hline Mato Grosso & 2.235 .832 & 126 & 05 & 66 & 961.596 \\
\hline Minas Gerais & 16.673 .097 & 853 & 54 & 636 & 9.694 .504 \\
\hline Paraíba & 3.305 .616 & 223 & 01 & 10 & 82.618 \\
\hline Paraná & 9.003 .804 & 399 & 16 & 274 & 4.214 .947 \\
\hline Rio Grande do Sul & 9.637 .682 & 467 & 02 & 55 & 890.621 \\
\hline São Paulo & 34.120 .886 & 645 & 08 & 79 & 1.900 .135 \\
\hline Santa Catarina & 4.875 .244 & 293 & 05 & 84 & 847.093 \\
\hline Total & 79.852 .161 & 3.006 & 91 & 1.204 & 18.591 .514 \\
\hline
\end{tabular}

Fonte: IBGE, 1996; Lima, 1998.

\section{A associação de municípios pequenos para a formação de Consórcios Intermunicipais de Saúde}

Os municípios consorciados são pequenos, em relação ao tamanho da população, como pode ser visualizado na Tabela 2. Para melhor entendimento da análise, usamos como parâmetro populacional (tamanho dos municípios) a seguinte denominação: Municípios Pequenos população inferior a 10.000 habitantes; Municípios de Médio Porte - população entre 10 e 50 mil habitantes e Municípios Grandes - população maior do que 50.000 habitantes.

Relacionando os dados de abrangência com os dados de tamanho de população, constatase que os consórcios atingem $12 \%$ da população brasileira em $22 \%$ dos municípios e $60 \%$ dos municípios atingidos possuem populações menores que 10.000 habitantes.

Considerando os dados encontrados, observa-se que a maioria das regiões consorciadas no país são formadas por municípios pequenos. Esta assertiva confirma o discurso da maioria dos prefeitos sobre a necessidade de formação de parcerias para a viabilização do sistema de saúde nestes municípios.

Verifica-se também que não existe nenhuma capital dos estados analisados contemplada com consórcios. Na fração dos 5\% de cidades brasileiras consorciadas que possuem população maior do que 50.000 habitantes, a maior cidade é Londrina, no Paraná, com 412.553 habitantes. Uberlândia, em Minas Gerais, apesar de ser a mais populosa, só participa do consórcio como referência para atendimento, sendo que o município em si não está consorciado.
Em relação às regiões metropolitanas envolvidas em consórcios, conforme preconiza o Ministério da Saúde (MS, 1997b:10), "Será feito um esforço especial para integrar na gestão plena, sob a forma de consórcios, os municípios que façam parte das regiões metropolitanas das grandes cidades brasileiras". Deve ser questionada a validade dessa afirmação, uma vez que os consórcios são formados a partir da necessidade de levar atendimento à saúde aos municípios que não têm condições para tanto.

\section{A organização dos municípios em consórcios de saúde: um fenômeno recente}

O estudo aponta que na década de 80 foram criados 5\% dos consórcios que estão em funcionamento até o momento. Em pleno processo de implantação das Ações Integradas de Saúde e em meio às discussões do Movimento de Reforma Sanitária, foi São Paulo o estado pioneiro na implantação de consórcios intermunicipais de saúde em Divinolândia (Consórcio Intermunicipal de Desenvolvimento Regional de São João da Boa Vista - CODERG -, 1985) e Penápolis (Consórcio Intermunicipal de Saúde da Região de Penápolis - CISA -, 1986), ambos funcionando plenamente até o momento deste estudo. Estes, por terem mais de uma década de formação, possuem uma estrutura organizacional que congrega toda uma rede assistencial, incluindo assistência básica nos municípios envolvidos.

Conforme pode ser visto na Tabela 3, 95\% dos consórcios estudados foram criados na década de 90, após a constituição do SUS e do in- 
centivo à sua implantação através da regulamentação das Leis Orgânicas da Saúde no 8.080/ 90 (Brasil, 1990a) e no 8.142/90 (Brasil, 1990b). Observamos que $70 \%$ dos consórcios do Brasil foram implantados nos anos de 1995 e 1996. Os consórcios de saúde são, de fato, um fenômeno desta década, configurando-se como uma alternativa de gestão do sistema vigente.

O Estado de Minas Gerais chegou a formar 28 consórcios em nove meses (1995), o que é um fato importante, considerando as muitas etapas necessárias para a implantação, que vão desde a manifestação de interesse pelos prefeitos, incluindo negociações políticas entre os mesmos, passando por discussões dentro de cada município para aprovação pelas Câmaras de Vereadores de Leis Autorizativas, sendo discutidos também nos Conselhos Municipais de Saúde, escolha de sede, atendimento de questões burocráticas, até a contratação de pessoal e aquisição de equipamentos, se este for o caso.

\section{Consórcios - um novo modelo}

de gestão para adequação de interesses e otimização de recursos escassos

Os consórcios funcionam, na sua maioria, para o atendimento ambulatorial especializado e hospitalar. A exceção fica por conta do consórcio da região de Penápolis, São Paulo (CISA). Este funciona com uma rede de atendimento em vários municípios, atingindo diversos níveis de complexidade, fazendo uma certa "desconcentração" da sede e utilizando estruturas e profissionais de outros municípios que o compõem. Cada prefeitura municipal se responsabiliza pela organização da sua rede básica, além de poder se beneficiar da estrutura administrativa do consórcio para a compra de materiais de consumo e permanente, contratação de pessoal, etc. (Almeida, 1989).

Embora não se tenha pretendido realizar estudos de caso separadamente em cada consórcio, a situação acima referida destaca a preocupação dos municípios consorciados daquela região em organizar as redes básicas próprias como parte do funcionamento geral.

Não há neste trabalho relato de outros consórcios que envolvam uma rede de serviços de saúde nos moldes de Penápolis, porém as inovações e ampliação dos serviços nos sistemas de consorciamento do país vão desde o "Trans-

Tabela 2

Classes de população de acordo com número

de municípios consorciados. Brasil, 1997.

\begin{tabular}{lrr}
\hline \multirow{2}{*}{ Classes de habitantes } & \multicolumn{2}{c}{ Municípios } \\
& $\mathrm{n}$ & $\%$ \\
\hline Até 5.000 habitantes & 361 & 30,0 \\
De 5.000 a 10.000 habitantes & 361 & 30,0 \\
De 10.000 a 20.000 habitantes & 263 & 22,0 \\
De 20.000 a 50.000 habitantes & 156 & 13,0 \\
Mais de 50.000 habitantes & 63 & 5,0 \\
Total & 1.204 & 100,0 \\
\hline
\end{tabular}

Fonte: Lima, 1998.

Distribuição dos Consórcios Intermunicipais de Saúde por estado e por ano de implantação. Brasil, 1997.

\begin{tabular}{|c|c|c|c|c|c|c|c|c|c|}
\hline & \multirow{2}{*}{$\begin{array}{l}\text { Rio Grande } \\
\text { do Sul }\end{array}$} & \multirow{2}{*}{$\begin{array}{l}\text { Santa } \\
\text { Catarina }\end{array}$} & \multirow[t]{2}{*}{ Paraná } & \multirow[t]{2}{*}{ São Paulo } & \multirow{2}{*}{$\begin{array}{l}\text { Minas } \\
\text { Gerais }\end{array}$} & \multirow{2}{*}{$\begin{array}{l}\text { Mato } \\
\text { Grosso }\end{array}$} & \multirow[t]{2}{*}{ Paraíba } & \multicolumn{2}{|c|}{ Brasil } \\
\hline & & & & & & & & $\mathrm{n}$ & $\%$ \\
\hline 1985 & - & - & - & 1 & - & - & - & 1 & 1,0 \\
\hline 1986 & - & - & - & 2 & - & - & - & 2 & 2,0 \\
\hline 1989 & - & - & - & 2 & - & - & - & 2 & 2,0 \\
\hline 1990 & - & - & - & - & - & - & - & - & - \\
\hline 1991 & - & - & - & 1 & - & - & - & 1 & 1,0 \\
\hline 1992 & - & - & 1 & 1 & - & - & - & 2 & 2,0 \\
\hline 1993 & 1 & - & 3 & - & 1 & - & - & 5 & 6,0 \\
\hline 1994 & 1 & - & 1 & - & 1 & - & - & 3 & 3,0 \\
\hline 1995 & - & - & 5 & 1 & 28 & 1 & - & 35 & 40,0 \\
\hline 1996 & - & 4 & 3 & - & 20 & 1 & - & 28 & 30,0 \\
\hline 1997 & - & 1 & 3 & - & 4 & 3 & 1 & 12 & 13,0 \\
\hline Total & 2 & 5 & 16 & 8 & 54 & 5 & 1 & 91 & 100,0 \\
\hline
\end{tabular}

Fonte: Lima, 1998. 
porte Saúde" e tratamentos de prevenção ortodôntica (em consórcios do Paraná), até atendimento de Saúde Mental (Embú, São Paulo).

Nos documentos obtidos no Ministério da Saúde, verifica-se uma ênfase em preconizar que a formação de consórcios intermunicipais de saúde atinja os níveis secundário e terciário de complexidade (MS, 1997b). Outro autor aponta ainda que a parceria entre o estado e os municípios para a formação dos consórcios deve ser sustentada organizacionalmente por uma Comissão Intergestores Bipartite Microrregional (Mendes, 1996). Neste sentido chamase a atenção para a necessidade de integrar as ações de saúde de forma que o indivíduo seja beneficiado tanto nos cuidados básicos como nos que exigem uma maior complexidade.

\section{Participação das Secretarias Estaduais de Saúde: parceria ou repasse de responsabilidades?}

Aproximadamente $75 \%$ dos consórcios estudados contaram com a participação da Secretaria Estadual de Saúde na sua constituição. Esta participação acontece através do repasse de verbas direto ou pela cessão de recursos humanos, materiais, equipamentos, apoio técnico, jurídico e também no sentido da formação dos consórcios, apresentando-se como política de governo. Este aspecto torna-se importante quando se verifica a tendência crescente de implantar consórcios a partir de incentivos criados em alguns estados para sua formação, conforme assinala Mendes (1996:287): “(..) $a$ crescente fragilidade das secretarias estaduais de saúde fez com que elas fossem, gradativamente, retirando-se da prestação dos serviços secundários e terciários ou tornando esses serviços de tão baixa qualidade, que obrigou os municípios a suprir essa deficiência dos sistemas. Assim, em boa parte e como mecanismos compensatórios, os consórcios surgiram no vácuo de secretarias estaduais de saúde ineficientes e ineficazes (...) Os Consórcios Intermunicipais de Saúde surgem espontaneamente, das necessidades dos municípios em resolver problemas $e$, não como resultado de políticas nacionais ou estaduais deliberadas. Só recentemente o Estado de Minas colocou o Consórcio como política de governo".

Em outros consórcios, no entanto, verificase a necessidade de organização das prefeituras dos municípios envolvidos, através da manifestação de interesse dos prefeitos, secretários de saúde ou dos conselhos municipais de saúde em resolver problemas de atendimento à saúde dos seus munícipes, buscando ajuda em cidades vizinhas ou alguma forma de solução.

A formação dos consórcios tem criado modelos que são ajustados às realidades e possibilidades de oferta de serviços regionais. Muitos interesses estão em jogo na complexa conjuntura de um significativo e emergente quadro de novos consórcios que estão tendo incentivos governamentais para sua implantação. Trata-se de uma prática inovadora de gestão, que cumpre uma etapa importante no processo de implementação do SUS e que necessita ser acompanhada pelos conselhos municipais de saúde para que funcionem efetivamente na prática cotidiana, atendendo à necessidade da população.

\section{A forma jurídica de organização dos consórcios: agilização dos processos burocráticos ou ameaça à estrutura do SUS?}

Segundo estudos de Torres (1995), um consórcio em si não tem personalidade jurídica, uma vez que ele constitui-se apenas de um acordo entre os municípios envolvidos, desta forma não tendo direitos e obrigações. É um ajuste. Os municípios, sim, têm personalidade jurídica. Se a intenção dos municípios não é uma mera reunião de recursos e sim a produção de recursos através da união, faz-se necessária a constituição de uma pessoa jurídica - no caso dos Consórcios Intermunicipais de Saúde, instituídos para compor o SUS, ou seja, sem fins lucrativos, constitui-se uma sociedade civil.

Para tanto, o chefe do executivo necessita de autorização da Câmara de Vereadores de cada município, assumindo, a partir de então, direitos e obrigações, podendo, inclusive, contratar pessoal, adquirir equipamentos, etc., dentro da legislação de concursos e licitações do Serviço Público (por se tratarem de recursos públicos).

É importante frisar que, para a grande maioria dos consórcios aqui estudados, a denominação Consórcio Intermunicipal deve vir acompanhada da expressão sociedade civil, uma vez que os mesmos constituem uma personalidade jurídica, de direito privado, sem fins lucrativos e que, portanto, utilizam recursos públicos oriundos dos municípios para viabilizar assistência à saúde da população. Este ponto pode ser verificado na fala de Torres (1995:36) sobre a constituição dos consórcios intermunicipais: "Assim, esse tipo de sociedade surgiria a partir da celebração de um contrato entre pessoas jurídicas de direito público (os municípios) e que se obrigariam mutuamente a combinar esforços 
e recursos para lograr fins comuns, consoante conceito dado pelo artigo 1.363 do Código Civil, certamente desprovidas de atividade comercial, isto é sem fins lucrativos e, uma vez elaborados os seus atos constitutivos, seriam registradas no Registro Civil (arts. 114 e seguintes da Lei 6.015/ 73), nascendo do registro a personalidade jurídica dessas entidades, isto é, aptidão plena para atuar na órbita jurídica e desvinculada juridicamente dos municípios que a criaram. Obviamente não seriam entidades supramunicipais, isto é, acima das entidades municipais que as integram, nem teriam autonomia politica, mas sim organizações de auxilio e de cooperação com as unidades políticas que as integram, formulando políticas e diretrizes intermunicipais, gerenciando planos e programas e realizando obras e serviços de interesse intermunicipal, como aliás já vem ocorrendo em várias regiões".

A formação dos Consórcios Intermunicipais de Saúde pressupõe que não seja criada mais uma entidade meramente burocrática e de difícil administração, como tantos órgãos públicos já existentes, e sim uma estrutura organizacional leve, eficiente, objetivando buscar a racionalidade dos recursos disponíveis e que propicie a participação popular.

Os estudos de Torres (1995) sugerem que a sociedade civil de direito privado denominada Consórcio Intermunicipal de Saúde deve ser constituída de uma diretoria ou conselho deliberativo, executivo, consultivo e fiscal, cabendo aos municípios estabelecerem a composição destas instâncias, sempre de forma igualitária para não haver predomínio de uns sobre outros. As estruturas encontradas nos consórcios estudados são as seguintes:

- Conselho de Prefeitos: Todos os consórcios estudados possuem na estrutura organizacional o Conselho de Prefeitos, sendo que, em 95\% dos casos, o conselho tem caráter deliberativo, ou seja, é responsável pela condução políticoadministrativa do consórcio. Esta instância de decisão tende a ser complexa pelo fato de ser constituída de chefes do executivo de diferentes partidos políticos e com interesses diversos. Este desenho tem dificultado a formação de consórcios em algumas regiões do país, pois os interesses "políticos" e até mesmo "clientelistas”, não raras vezes, sobrepujam os interesses da população no que diz respeito ao atendimento de saúde.

A constituição do município sede representa um fator interessante na relação de poder dos prefeitos. Em $85 \%$ dos consórcios, a sede está localizada nos municípios mais populosos onde, possivelmente, os prefeitos tenham concentrado mais poder.
- Conselho Executivo: Também chamado de Conselho de Secretários Municipais de Saúde ou Conselho Técnico Consultivo. Esta parte da estrutura é composta, na maioria das vezes, pelo Secretário Municipal de Saúde ou por um representante técnico do governo local. As atribuições são de natureza técnico-operacional, necessitando de conhecimentos mais específicos na área de saúde por parte dos conselheiros.

Existem consórcios nos Estados de Santa Catarina e Paraná em que os secretários municipais de saúde exercem a função de conselheiro fiscal, o que constitui-se uma incoerência, sob o ponto de vista da dificuldade de uma pessoa desempenhar um cargo público dentro do município e exercer poder de fiscalização sobre o seu chefe imediato do poder executivo.

Grande parte dos consórcios do Estado do Paraná adotou a estrutura do Conselho Técnico Consultivo Paritário para exercer as funções técnico-operacionais e, na maioria das vezes, é composto pelos secretários municipais de saúde.

- Conselho Fiscal ou Conselho Curador: Esta é a parte da estrutura que possui a maior diversidade de tipos de composição nos consórcios analisados. Constata-se que $90 \%$ dos consórcios intermunicipais de saúde do país possuem algum tipo de conselho fiscal, mesmo que sua composição seja discutível.

Nesta instância é que se pode garantir as conquistas da Constituição Federal de 1988 (Brasil, 1988) e a sua confirmação pelas Leis Orgânicas da Saúde no 8.080/90 (Brasil, 1990a) e no 8.142/90 (Brasil, 1990b), no que diz respeito a participação e controle social da população nos Conselhos Municipais de Saúde, estendendo a participação para a formação de um Conselho Intermunicipal de Saúde e atuando como conselho curador ou fiscal dos Consórcios Intermunicipais de Saúde. São espaços privilegiados onde os atores envolvidos discutem e fiscalizam os encaminhamentos institucionais, conquistando espaços de negociação para compor seus objetivos de atendimento integral à saúde.

Como já foi relatado acima, encontramos consórcios em que a fiscalização é exercida pelos prefeitos e o conselho deliberativo é exercido pelos secretários municipais de saúde; outros, numa inversão hierárquica, os secretários fiscalizam os prefeitos. A grande maioria, no entanto, é constituída de conselhos fiscais formados a partir de membros dos Conselhos $\mathrm{Mu}$ nicipais de Saúde.

Um outro ponto interessante refere-se aos membros das Câmaras de Vereadores fazendo 
parte dos Conselhos Fiscais, o que seria ilegal segundo publicação do Ministério da Saúde (1997c:24): "O Conselho Fiscal, além de fazer parte das exigências decorrentes da criação da pessoa jurídica, é o órgão que fiscaliza internamente o consórcio e, portanto, não pode ser integrado pelas mesmas pessoas que autorizam o repasse e a utilização de recursos e exercem a fiscalização externa à pessoa jurídica. Assim, o Conselho Fiscal não deve ser integrado por pessoas que pertençam ao Poder Legislativo ou ao Poder Judiciário, tendo em vista a independência dos poderes. Conforme está previsto no Artigo 20 da Constituição Federal ... são poderes da União, independentes e harmônicos entre si, o Legislativo, o Executivo e o Judiciário".

Recursos humanos e financeiros: estratégias para a implantação dos consórcios?

A escassez de recursos humanos no interior do País talvez seja o fator mais relevante para a instituição dos Consórcios Intermunicipais de Saúde nos municípios pequenos. Dos sete estados estudados, apenas a Paraíba não enviou informações detalhadas sobre recursos humanos envolvidos no processo de consorciamento dos seus municípios. Nos demais estados, os dados não são precisos com relação à quantidade de pessoas envolvidas, mas todos são unânimes em relatar a sua importância neste processo e para o funcionamento do sistema de saúde.

O Paraná não enviou dados sobre a contratação de funcionários pelo regime da Consolidação das Leis do Trabalho. Nos demais estados, existem contratações por este regime, sendo que em São Paulo elas são maioria.

A prática de contratação de celetistas em consórcios é amplamente empregada, pois o regime jurídico destas instituições é de direito privado, mesmo que a natureza dos recursos seja pública. Os municípios, por sua vez, também podem ceder seus servidores para prestar serviços nesta sociedade, desde que seja de comum acordo das partes e seja devidamente oficializado (Torres, 1995).

Observa-se em São Paulo e Minas Gerais a existência de funcionários em regime estatutário cedidos aos consórcios pelas Prefeituras Municipais. Os funcionários cedidos pelos Governos Estaduais foram relatados por todos os estados. Já a presença de funcionários federais lotados nos consórcios é descrita no Paraná, São Paulo, Minas Gerais e Mato Grosso. No Rio Grande do Sul e Santa Catarina encontram-se consórcios que compram serviços profissionais especializados para o atendimento nos municípios.
De um modo geral, a falta de profissionais especializados é recorrente no discurso de grande parte dos gestores, para justificar a formação dos Consórcios Intermunicipais de Saúde. No entanto, a maioria dos consórcios está em regiões onde, historicamente, existe excesso de profissionais de saúde, como nas regiões Sul e Sudeste, que concentram simultaneamente o maior número de profissionais e também possuem o maior aparato tecnológico disponível no país, com serviços de alta complexidade concentrados nos grandes centros urbanos. Esta constatação feita por diversos autores em décadas passadas pode ser expressa pelos estudos de Médici (1987). Este autor aborda a alta concentração de médicos nas regiões mais desenvolvidas e, conseqüentemente, a falta destes profissionais nas regiões mais carentes do país, bem como relata situações de diversas cidades brasileiras sem nenhum profissional médico.

Nesta perspectiva, ao citar os médicos, pode-se estender a mesma avaliação aos demais profissionais de saúde que trabalham no interior do país, uma vez que os médicos são parte fundamental da equipe para o atendimento integral à saúde da população. Em recente pesquisa da Fundação Oswaldo Cruz (FIOCRUZ) / Conselho Federal de Medicina (CFM), estes dados foram confirmados pela excessiva urbanização dos profissionais médicos nas maiores capitais brasileiras $(65,9 \%)$ e pela constatação de que, dos quase 200 mil médicos do Brasil, aproximadamente $75 \%$ estão nas regiões Sudeste e Sul, sendo que quase $50 \%$ nos Estados do Rio de Janeiro e de São Paulo (Machado, 1997).

Partindo destes dados, existe uma dissonância entre o discurso e a realidade no que diz respeito à formação de consórcios. Como justificar a criação de um consórcio pela falta de recursos humanos, se a maioria dos existentes localiza-se justamente nas regiões onde há maior concentração de profissionais de saúde e recursos tecnológicos do país?

Com relação ao financiamento, pode-se observar que grande parte dos Consórcios Intermunicipais de Saúde trabalhados tem financiamento do Sistema Único de Saúde através do Sistema de Informação Ambulatorial/Sistema de Informação Hospitalar (SIA/SIH). Estes recursos são repassados aos municípios diretamente ou através das secretarias estaduais de saúde.

Os consórcios atribuem a contrapartida de fundos oriundos do Tesouro Municipal como participação municipal. Os percentuais variam muito, alguns são de acordo com critérios populacionais, outros com cotas fixas aprovadas pelas Câmaras de Vereadores, outros ainda de acordo com os atendimentos efetuados no mês. 
Os recursos repassados dos governos estaduais para os Consórcios Intermunicipais que contam com este apoio também variam muito, mas na maioria compreendem repasses de estruturas físicas, materiais permanentes, aquisição de equipamentos, medicamentos, materiais de consumo, pequenas reformas e até mesmo contratação de pessoal especializado e pagamentos salariais dos mesmos.

Recente estudo sobre financiamento do setor de saúde relata as desigualdades alocativas no repasse de verbas nas diferentes regiões do país, principalmente no que diz respeito às transferências ambulatoriais, onde o Sudeste se apropria de $51 \%$ dos recursos. Uma maior equidade foi observada nos pagamentos por internações, onde o equilíbrio entre as regiões está mais próximo de ser alcançado (Ribeiro \& Costa, 1999).

Os autores descrevem também diferenças na distribuição geral de recursos por tipo de município. Um conjunto de procedimentos ambulatoriais, no período estudado, em localidades com população superior a 200.000 habitantes apresenta valores médios de R\$25,74 por habitante, enquanto as pequenas somam R\$ 14,62. E concluem: "Este conjunto de dados favorece a constituição de consórcios, na medida em que o acesso a recursos do SUS permanece ainda muito concentrado no nível local, em termos de dimensões municipais. Além disso, com a prometida remuneração dos serviços ambulatoriais básicos pelo SUS por base populacional (através da implantação do Piso Assistencial Básico previsto pela NOB 96), espera-se a correção de disparidades, com a maioria dos municípios pequenos passando a receber maiores recursos. O efeito combinado de indução institucional, maior disponibilidade de recursos nas mãos de pequenos e médios municípios e necessidade de agregação para acesso a itens de maior complexidade, deve estimular uma celerada multiplicação de consórcios de saúde no país" (Ribeiro \& Costa, 1999:14).

Realmente a multiplicação dos consórcios tem acontecido na prática, mesmo que em formatos diferenciados e às custas de interesses que nem sempre atendem às necessidades da população no seu direito de assistência à saúde. Existem consórcios, como o de Betim em Minas Gerais, que funcionam sem ter personalidade jurídica de direito privado, ou seja, municípios associam-se em um pacto que concilia interesses sem visar a produção de recursos para viabilizar a saúde da população. Por certo, este tipo de acordo só resulta em benefícios quando acordados em uma coesão política que permita a conjugação de interesses entre os municípios envolvidos e a população assistida.

\section{Considerações finais}

Com este trabalho, foi possível mapear a situação dos Consórcios Intermunicipais de Saúde no Brasil. O estudo revelou as diferenças, os processos decisórios e as especificidades de cada Estado. Portanto, ao falar de consórcios, deve-se considerar estas variáveis e tomá-las como ponto de partida para qualquer análise.

O processo de descentralização promovido pela regulamentação do sistema público de saúde na Constituição foi efetivado de maneira desigual nas diferentes regiões do país, levando os municípios do interior, que até então não tinham uma participação efetiva nas ações de saúde, a buscarem alternativas para implantar o SUS. Neste percurso, a associação com outros municípios representou a parceria ideal para otimizar estruturas e equipamentos de maior complexidade tecnológica, resolver problemas de recursos humanos, financeiros e facilitar o acesso aos serviços de saúde para um maior número de pessoas.

Os Consórcios Intermunicipais de Saúde são uma prática de gestão inovadora dentro do SUS. Ora apresentando-se como associações para reunir recursos e prover o sistema de saúde, ora constituindo-se como entidades civis de direito privado para reunião e produção de recursos, utilizando-se de verbas públicas ou de doações para serem usadas exclusivamente no provimento da saúde pública, valendo-se das leis que regem as licitações e contratos.

O Brasil conta hoje com 91 consórcios distribuídos em sete estados, a saber, Rio Grande do Sul, Santa Catarina, Paraná, São Paulo, Minas Gerais, Mato Grosso e Paraíba.

Os consórcios estudados abrangem $22 \%$ dos municípios do Brasil e $12 \%$ da população brasileira, o que confirma a grande participação de municípios pequenos. A maioria concentrase nas regiões Sul e Sudeste do país, sendo que a Região Norte não possui nenhum, a Nordeste possui apenas um e a Região Centro-Oeste cinco consórcios. Tal fato contraria o discurso da maioria dos gestores que justifica a implantação de consórcios para suprir a falta de recursos humanos e financeiros, uma vez que, no Sul e Sudeste estão concentrados a maior parte dos recursos tecnológicos e humanos da saúde.

O Sudeste concentra $68 \%$ dos consórcios do país e, destes, $87 \%$ estão em Minas Gerais, o restante em São Paulo. O Estado de Minas Gerais adotou esta modalidade de gestão como política no atual governo e, segundo propaganda do próprio executivo mineiro, são repassados incentivos oriundos do ICMS (Imposto sobre a Circulação de Mercadorias e Serviços) co- 
mo prêmio aos municípios que aderirem à prática de consorciamento. No entanto, isso não garante que todos estejam cumprindo as necessidades de atendimento da população. $\mathrm{O}$ Estado de São Paulo, por outro lado, foi o pioneiro ao implantar esta forma de associação na década de 80, quando o Movimento de Reforma Sanitária discutia as mudanças no sistema de saúde.

Nessa perspectiva, seria interessante pensar na conjuntura política em que estão sendo estruturados os consórcios e as reais necessidades daqueles municípios de se organizarem desta forma. Chama atenção o caso de Minas Gerais, onde, em apenas três anos (95, 96 e 97), sob a mesma administração, foram criados 52 consórcios, abrangendo 587 municípios, ou seja, aproximadamente $70 \%$ dos municípios do Estado. Torna-se fundamental um questionamento: teriam estas localidades necessidades e condições para a existência deste tipo de associação? Estariam esses consórcios em pleno funcionamento e as entidades que atuam no controle social foram consultadas e têm assento nos conselhos? Ou esta é mais uma implementação de agenda política do governo?

Por outro lado, o modelo de consorciamento de Penápolis, São Paulo constitui-se uma tipologia que congrega uma verdadeira rede de assistência, com atendimento básico e de maior complexidade distribuída pelos vários municípios que a compõem, facilitando o acesso da população e conjugando interesses de vários prefeitos em possuírem estruturas de atendimento à saúde. Esta parece ser a fórmula de consorciamento que mais se ajusta ao preceito de integralidade preconizado pelo SUS.

Fato que merece destaque é o de que não há nenhuma capital envolvida no modelo de consorciamento. Isto destaca ser a prática de consórcios uma tendência dos municípios do interior do país, em um movimento de desconcentração do atendimento nos centros urbanos e, por conseguinte, tornando inviável o mesmo processo de investimento nas regiões metropolitanas, que sabidamente possuem grande aparato tecnológico e de profissionais da área de saúde.

A "figura jurídica" adotada pela maioria dos consórcios, apesar de agilizar os processos burocráticos da gestão, torna-os alvo fácil de interesses clientelistas de gestores inescrupulosos, facilitando a contratação de pessoal sem concurso, aquisição de materiais sem licitação e outras práticas que ameaçam a transparência da utilização de recursos públicos, o que deve ser alvo de constante vigilância por parte da população organizada.
Dois exemplos chamam a atenção pela diferente estrutura jurídica adotada: Betim, em Minas Gerais, que optou por não criar uma personalidade jurídica e os municípios reuniramse em associação, e o Consórcio Região Centro no Rio Grande do Sul, que é uma sociedade civil de direito público. Portanto, não existe um modelo único de implantação dos consórcios de saúde. Dependendo dos interesses e da realidade em que estão inseridos, podem se constituir pessoa jurídica ou não.

É notório que a formação dos Consórcios de Saúde depende da conciliação de interesses entre os atores envolvidos. É necessário que exista vontade por parte dos gestores em compartilharem ações que visem otimizar recursos, ajustes políticos e partidários dos prefeitos e vereadores, competência técnico-administrativa e engajamento dos profissionais de saúde ao SUS.

O Estado de Mato Grosso, não obstante outros avanços proporcionados pelo surgimento dos consórcios, constitui-se na maior expressão de viabilização do acesso ao atendimento de saúde, devido a enorme distância existente entre os municípios e entre estes e a capital. Ressalta-se a necessidade de implantação de consórcios em outros estados do Brasil, principalmente nas regiões Norte e Nordeste, pois estas possuem problemas semelhantes de acesso motivados pela distância e carências entre os municípios.

Desta forma, para que os consórcios representem uma prática mais includente dentro do SUS, eles devem partir de uma cooperação acordada de interesses, mas que tenham em comum as premissas de integralidade, universalidade, eqüidade e controle social, partindo do princípio que representa uma conjugação de esforços para a descentralização. Assim, os consórcios não se constituem em uma outra esfera de poder dentro do SUS, mas sim combinam poderes fragmentados para viabilizar a saúde dentro de uma realidade específica.

Demonstrando esta afirmação, existem exemplos de consórcios que estão representando inovações ao sistema público de saúde dentro das suas realidades locais. A viabilização de farmácias de manipulação, ônibus-saúde para o transporte de pacientes, aparelhos para prevenção ortodôntica, ambulatórios e hospitais de saúde mental, estudos epidemiológicos para um melhor direcionamento de ações de saúde, centros de produção e distribuição de hemoderivados, casas de espera para pacientes em recuperação pós tratamento e centro de formação de recursos humanos, representam efetivas mudanças de prática e de gestão comprometida com a população. 
Não se pode perder de vista no processo de consorciamento a premissa de integralidade do SUS. Algumas práticas de governo têm ainda o caráter centralizador que marcou a saúde na década de 70, quando o Estado distribuiu e fragmentou a atenção à saúde em programas focalizados, instituindo-os como "milagres para a resolução dos problemas de saúde da população”. Os consórcios não são um novo milagre, constituindo-se apenas em uma forma de conciliar interesses e otimizar recursos que levem à concretização do SUS no interior do país.

Enfim, o estudo, apesar do caráter exploratório que apresenta, pôde verificar que esta modalidade de gestão é, reconhecidamente, uma forma alternativa para a racionalização e operacionalização de recursos, sejam eles humanos, financeiros ou de outra natureza. Exis-

\section{Agradecimentos}

A autora agradece aos professores Nilson do Rosário Costa, Maria Helena Machado e José Mendes Ribeiro. te a clareza da necessidade de um maior aprofundamento em diversas questões que se apresentaram no decorrer deste estudo e que dependiam, além de um maior tempo de trabalho, mais especificidade e detalhamento que poderão ser elucidados em estudos futuros.

Vale a pena ressaltar que, para um país de dimensões continentais, com todas as suas carências e soluções pouco compatíveis com esta realidade, implementar um Sistema de Saúde equânime, integral, universal e com ampla participação social é, no mínimo, uma tarefa complexa e demorada de alcançar.

A opção pela alternativa dos consórcios na área de saúde parece um dos caminhos adequados. Eles surgem nesta conjuntura com a perspectiva de equacionar necessidades e viabilidades nesta diversificada e complexa realidade brasileira.

\section{Referências}

ALMEIDA, C. M., 1989. Os Atalhos da Mudança na Saúde do Brasil/Serviços em Nível Local: 9 Estudos de Caso - Uma Análise Comparativa. Rio de Janeiro: Organização Pan-Americana de Saúde/Organização Mundial de Saúde.

ALMEIDA, F. H. M., 1958. Consórcio Municipal. Revista de Direito Administrativo, 52:525-531.

BRASIL, 1988. Constituição (1988). Constituição da República Federativa do Brasil. Brasília: Senado Federal.

BRASIL, 1990a. Lei no 8.080, de 19 de setembro de 1990. Lei Orgânica da Saúde. Dispõe sobre as condições para a promoção, proteção e recuperação da saúde, a organização e o funcionamento dos serviços correspondentes e dá outras providências. Brasília: Diário Oficial da República Federativa do Brasil, v. 128, n. 182, pp. 18055-18059, 20 set. Seção I, pt. 1 .

BRASIL, 1990b. Lei no 8.142, de 28 de dezembro de 1990. Dispõe sobre a participação da comunidade na gestão do Sistema Único de Saúde (SUS) e sobre as transferências intergovernamentais de recursos financeiros na área da saúde e dá outras providências. 02 Outubro $2000<$ http://www. saude.gov.br>. 
CARVALHO, G. I. \& SANTOS, L., 1995. Sistema Único de Saúde. Comentários à Lei Orgânica da Saúde (Lei 8.080/90 e Lei 8.142/90). 2a Ed. São Paulo: Editora Hucitec.

COSTA FILHO, J. P., 1955. Consórcios intermunicipais para a solução de problemas regionais paraibanos. In: Relatório do I Congresso Estadual dos Municípios Paraibanos, pp. 1-2, Campina Grande: Comissão de Planejamento Municipal.

GONTIJO, L. T.; DONNINI, O.; RIBEIRO, J. M. \& CUNHA, J. P., 1994. Penápolis: Sete cidades e uma história em comum. Revista Espaço para a Saúde, 3:11-13.

IBGE (Fundação Instituto Brasileiro de Geografia e Estatística), 1996. Anuário Estatístico do Brasil, $v$. 56. Rio de Janeiro: IBGE.

LIMA, A. P., 1998. Os Consórcios Intermunicipais de Saúde e o Sistema Único de Saúde. Dissertação de Mestrado, Rio de Janeiro: Escola Nacional de Saúde Pública, Fundação Oswaldo Cruz.

MACHADO, M. H., 1997. Os Médicos no Brasil: Um Retrato da Realidade. Rio de Janeiro: Editora Fiocruz.

MÉDICI, A. C., 1987. Estrutura e dinâmica da força de trabalho médico no Brasil na década de setenta. In: Textos de Apoio/Planejamento I/Recursos Humanos em Saúde (A. C. Médici, org.), pp. 89-123, Rio de Janeiro: Programa de Educação Continuada/Escola Nacional de Saúde Pública, Fundação Oswaldo Cruz.

MENDES, E. V., 1996. Uma Agenda para a Saúde. São Paulo: Editora Hucitec.

MS (Ministério da Saúde), 1991. Resolução PR/INAMPS № 258 de 07/01/91. Norma Operacional Básica 01/91. Brasília: MS.
MS (Ministério da Saúde), 1993. Portaria MS № 545 de 20/05/93. Norma Operacional Básica 01/93. Brasília: MS.

MS (Ministério da Saúde), 1996. Reforço à Reorganização do SUS - REFORSUS. Manual de Operação. Brasília: Secretaria de Assistência à Saúde, Ministério da Saúde.

MS (Ministério da Saúde), 1997a. Portaria MS № 2.203. Norma Operacional Básica/SUS. № 01/96. Brasília: MS.

MS (Ministério da Saúde), 1997b. 1997 - O Ano da Saúde no Brasil. Ações e Metas Prioritárias. Brasília: MS.

MS (Ministério da Saúde), 1997c. Os Consórcios e a Gestão Municipal em Saúde. 1a Ed. Brasília: MS.

RIBEIRO, J. M. \& COSTA, N. R., 1999. Consórcios Intermunicipais no SUS. Texto para Discussão no 665. Brasília: Instituto de Pesquisa Econômica Aplicada.

TAVARES, H., 1977. Planejamento microrregional e consórcios intermunicipais. Revista de Administração Municipal, 24:53-64.

TORRES, L. A. G., 1995. Consórcio Intermunicipal: Estudos, Pareceres e Legislação Básica. Informativo Jurídico do Centro de Estudos e Pesquisas de Administração Municipal (CEPAM) no 11. São Paulo: CEPAM/Fundação Prefeito Faria Lima.

VIANNA, A. L., 1996. SUS: Entraves à descentralização e propostas de mudança. In: Federalisamo no Brasil. Descentralização e Políticas Sociais (R. B. A. Affonso \& P. L. B. Silva, org.), pp. 269-295, São Paulo: Fundação de Desenvolvimento Administrativo. 